\title{
An action research project to explore the effect of an established pre- assessment intervention with undergraduate occupational therapy students
}

\author{
Anita Volkert, Leeds Metropolitan University
}

\begin{abstract}
This action research study was conducted with 40 undergraduate occupational therapy students completing a Level 6 module. Following identification of the issue of student performance in the module assessment, an emancipatory action research cycle was implemented (Atwal, 2002), consisting of a pre-assessment intervention (Rust et al., 2003) to enhance student understanding of the assessment criteria being used. Results were gathered via reviewing student performance and comments from student module evaluations. Reflection and wider implementation of the action was then completed. The project resulted in an indication of improvement in student performance in the module assessment and a reported increase in student engagement. Findings suggest the need to include some form of formative feedback or pre-assessment intervention in all undergraduate modules in health and social care education. Recommendations for further research are discussed.
\end{abstract}

Keywords: Action research; assessment; formative feedback.

\section{Introduction}

This small-scale action research project arose out of questions arising while working on a Level $6 \mathrm{BSc}$ (Hons) module with pre-registration occupational therapy students. The assessment for the module required the students to write a 2000 word literature review on a topic related to the module material. They were also required to provide an additional resource (e.g. leaflet, website etc) to support the literature review. Initial results and module evaluations suggested that students found this assessment task difficult, and that student performance was an issue, leading to the following questions:

- Why did the students find this assessment so difficult to complete successfully? There was nearly full attendance at teaching sessions, and the module content had been well evaluated.

- What preparation had the students had prior to and during this module in order for them to complete an assessment task successfully?

Using an action research approach, it was decided to trial a pre-assessment intervention as developed by Rust et al. (2003) in the next running of the module in order to improve students' understanding of the assessment criteria and improve their performance in the task set. The preassessment intervention was not original and already had an established evidence base. There is, however, a lack of any kind of pedagogical evidence in the both the occupational therapy and health professional literature, particularly around assessment methods (Samuelowicz, 1987; Swanson et al., 1998; Seale et al., 2000; Chung \& Chow, 2004). 
Rust et al. (2003) originally set out to make assessment methods clearer and more transparent to all individuals involved (teachers and students), conducting a two year project that involved the transfer of knowledge of the assessment process and criteria through a structured process. The aim was to improve student performance through enhancing the ability to assess the work of others and, in consequence, the students' ability to assess their own work against given marking criteria. The initial study has since been replicated by the authors, with further richness of results (Price et al., 2007). Their findings show that students who undertake the pre-assessment intervention demonstrate a significant improvement in performance compared with those who do not, even though base line comparison of the performance of the two groups, undertaken prior to the intervention, show no significant difference, and that performance improvement is sustained up to a year later at a significant, if somewhat diminished, level.

Rust et al. (2003) were working within a business module; there is however little pedagogical discussion or evidence in the occupational therapy or health professional education literature about making use of different assessment methods. What evidence there is in the field focuses on discussing student motivation; different curriculum approaches; assessing international students; and the use performance-based assessment in health care to evaluate fieldwork (Samuelowicz, 1987; Swanson et al., 1998; Seale et al., 2000, Chung \& Chow, 2004).

Although Rust et al.'s work (2003; O’Donovan et al., 2004; Price et al., 2007) has attracted criticism in terms of dismissing the importance of the teacher's tacit knowledge involved in assessing work, they counter that fairness is an issue within modern educational regimes, and that students have few opportunities to develop evaluative knowledge themselves at any point in their education. It can be argued that this is a particularly important skill to develop during the education of health care students, who will need to be able to evaluate their own performance in practice following qualification, usually against a set of standards. In addition, Rust et al. (2003; Price et al., 2007) argue that methods such as dialogue, observation, practice and imitation have long been used to facilitate consistency and reliability in assessment, and this is certainly true in the education of health care practitioners (Swanson et al., 1998).

Due to the massification of higher education, students are now more diverse on entry to university, and student achievement on entry is no longer such a useful indicator of standards to expect in higher education (James, 2007; Leathwood, 2005). James (2007) recommends the intensive communication of expectations and the highly strategic use of assessment to explain the curriculum and to communicate what will be rewarded in assessment. This is an approach that fits with the pre-assessment intervention and concurs with Rust et al.'s (2003; O'Donovan et al., 2004; Price et al., 2007) view.

However, assessment ideally needs to be not just something done to learners, but something done with and done by learners (Harris \& Bell, 1990). Mowl (1996) recommends the use of innovative assessment techniques in courses such as health and medicine, stating that a single, allencompassing grade for a piece of assessed work in these fields is actually inappropriate due to the fact that the student has no opportunity to learn from their strengths and weaknesses that way. Mowl (1996) argues that enhanced communication between teacher and learner, and empowerment of the learner, creates deep, motivated, committed learners who are enterprising, 
skilled and active participants in the learning process. Similarly, Knight (2002) argues that student achievement is related first and foremost to engagement, that learners do not just engage as individuals with the material, but as communities and networks, and through exchanges with others, meaning that engagement with learning is not just about individual time or attendance. However, this kind of learning is highly unpredictable, and cannot be easily measured, causing further issues with assessment.

A pre-assessment intervention can be considered as a type of formative feedback, or feedforward mechanism within a curriculum. Orsmond et al. (2005) found that students use formative feedback to enhance motivation, to enhance learning, to encourage reflection, and to clarify understanding. They found that students also use it to enrich their learning environment, and to engage in further enquiry into their field of study.

Students on the programme studied in this paper usually received feedback on modules after a module had finished - meaning its use for that particular module was limited, and there are queries about how much students carry over feedback within modular programmes. Thus more formative feedback opportunities may benefit student motivation, learning, reflection and understanding, as well as enrich student learning and spur students on. Indeed, Caygill and Eley (2001, p.1) discuss the use of formative assessment as a 'diagnostic tool' as opposed to the usual role of summative assessment to report progress, certify, and add accountability and monitoring. They argue that formative assessment practices allow teachers to cater for individual need, and to promote attention to student strengths and weaknesses. They go on to review different methods of assessment, comparing a broadly traditional model of multiple choice and short answer questions and essays to a more modern model of interviews, portfolios, use of equipment and team tasks within the science subject areas. These are criticised as being resource-intensive; subjective; difficult to mark; and open to interpretation, although have also been shown to address equality and diversity issues more effectively (Caygill \& Eley, 2001), and to bear more relationship to work-related activities within the professions (Swanson et al., 1998).

\section{Aim}

Thus, the aim of this action research study was to enhance occupational therapy student performance in an assessment task by improving their understanding of the assessment criteria via a pre-assessment intervention (as developed by Rust et al., 2003).

\section{Method}

Action research is a style of research, rather than a specific method, and lends itself to research in the education, health and social care fields. Carr and Kammis (1986) define it as a form of self-reflective enquiry undertaken by those in social settings in order to improve their own practices, their understandings of these practices, and the situations in which these practices are carried out. The investigator is required to develop methods and strategies in the field, due to action research's dependency on the personal and interpersonal skills of the investigator (Meyer 2000). The reflective nature of this style of research suited the issue identified, and the personal style of the researcher, although action research has also been criticised as being ill-defined as a research style (Holter \& Schwarz-Barcott, 1993), leading to many divergent approaches or uses 
which still describe themselves as action research. Hart and Bond (1995) describe the style as problematic when researchers are unclear about the constraints and possibilities of these many different ways of undertaking action research, particularly as there is a risk researchers may move from one type to another in an unplanned way through the different phases of development of a piece of research. Hence, much action research has been criticised as being of relatively poor quality, and sloppy, and a poor use of resources (Adelman 1989; Eden \& Huxham 1993; Winter, 1989). The complex, multi-dimensional nature of many action research studies, whilst adding richness to the body of knowledge on one level, could also be a drawback in terms of difficulty classifying individual studies, making dissemination difficult (Meyer 2000; Winter, 1989). Action research in education has also been soundly criticised for failing to improve, despite many years of implementation, our understanding of what really influences the learning process in teaching and learning (Cohen et al., 2000).

One of the action research models that attempts to resolve many of these issues (Atwal, 2002) is the emancipatory action research model, which provides a framework for understanding organisational change and best practice, and encourages organisational learning, and the development of the 'learning organisation' (Zuber-Skerritt, 1996; Lewin, 1952; Beer et al., 1990). This model is designed for organisation change, and as the intention in this research study was to pilot a technique which, if successful, could be rolled out for use by other module leaders, and at an organisational level, it was chosen as an appropriate model of action research for the purposes of this study. The 5 steps of emancipatory action research are:

1. Strategic Planning

2. Implementing the Plan (Actions)

3. Observation

4. Evaluation

5. Self-evaluation - (critical and self-critical reflection.)

Following completion of these steps, the researcher/s then make decisions for the next cycle of action research, and the revised plan is implemented and followed by action and reflection (Zuber-Skerritt, 1992).

The action research took place within a Level 6 module of a BSc (Hons) Occupational Therapy programme, at a university in the UK which had traditionally been a centre of vocational training. The researcher had over time built up an insider view of the organisation.

Prior to the action research, an issue was identified - performance at an assessment task within a Level 6 module. The issue also fitted with the organisation's emphasis on assessment practices as a theme for staff development and improvement.

The action research comprised:

1. The implementation of a previously developed pre-assessment intervention (Rust et al., 2003) with a class of 40 Level 6 Occupational Therapy students.

2. The evaluation of this pre-assessment intervention, via student performance and their feedback on module evaluation forms. 
Ethical approval was discussed with the project supervisors and agreed as per institution guidelines.

\section{Implementing the Action Research Plan}

The key components of the plan were to:

1. Timetable a 90 minute session mid-way through the module for a pre-assessment intervention.

2. One week prior to the session: to place on the Virtual Learning Environment (VLE) two sample assignments, plus assessment criteria, and to ask the students to individually mark these in their own time, and to provide a grade with justification for the grade.

3. The pre-assessment intervention session divided students into small groups to share and discuss the grades and justifications each student had given. Each small group then attempted to agree a mark, which the tutor recorded on flipchart paper. The tutor then deconstructed the marking criteria in detail, and asked students if they would change their mark based on this, and recorded any changes.

4. The tutor then revealed actual mark for the sample assessments, and justification, and placed annotated copy on the VLE.

5. At the end of the module, students submitted their coursework, and completed a Module Evaluation, with the option to comment on the pre-assessment intervention.

6. Student performance and Module Evaluations were collated.

7. The process was shared with the wider teaching team at a bi-annual Staff Development event, enabling other team members to incorporate it into their own module teaching and assessment practices. The researcher and wider teaching team were able to engage in reflective discussion about whether they continued to use the process in the current form, or make modifications based on the outcome of the action research. These included deciding whether to use the process in every module, or just some, or whether to use different methods of formative assessment instead of the pre-assessment intervention.

\section{Results}

Student performance was improved in the cohort that undertook the pre-assessment intervention. There were fewer fails, and more student achieved a merit mark or higher. This is in line with the findings of Rust et al. (2003; Price et al., 2007), although it must be noted that this study was completed with only one cohort of students and as such cannot be generalised.

Comments from student evaluations fell into three broad categories of issues relating to student performance, engagement and support. Not all students evaluated the pre-assessment intervention positively.

\section{Performance}


There were some indications that the pre-assessment intervention helped students to gain valuable skills of self-evaluation:

'The halfway session was very good/useful and helped a great deal with writing assignment. It allowed me to know where I was going wrong and how I could improve it/know whether I was on right track.'

It also demonstrated the importance of assessment results to modern students in higher education, although there was much less of this than the author expected:

'Looking forward to getting my results to see if half way session made any difference/is reflected in my mark'.

\section{Engagement}

More strongly reflected in the module evaluations were the benefits the pre-assessment intervention had brought in terms of student engagement:

'Made doing the assessment enjoyable'.

'Half way session helped enhance understanding'.

'Halfway session was motivating'.

'Made me more confident in my work'.

\section{Support}

Additionally, there were a number of comments that related to the sense of support provided by the pre-assessment intervention, including, interestingly, reflections on the students' own ability to use and take up the session:

'Able to ask questions on assignment and use of VLE was good'.

'Helpful to have marking criteria/guidelines explained-became clearer'.

'First time during course that felt have had constructive session on preparing for assessment before an essay hand in'.

'Half was session should be done for every module'.

'Wish I'd made more of the half way session'.

However, not all students commented positively on the pre-assessment intervention, and less positive comments included:

'Seeing a sample resource didn't necessarily help, made me panic'. 
'Wanted feedback on my own draft rather than using sample assessment'.

'Still felt focussed on the summative piece'.

'Still uncertain as to what was expected from different markers'.

This suggested that a range of opportunities for formative assessment may be required.

\section{Discussion}

The Importance of Formative Feedback Opportunities

Current evidence supports the inclusion of formative type experiences within university curricula, of which the pre-assessment intervention chosen was one (Caygill \& Eley, 2001; Rust et al., 2003; Orsmond et al., 2005; Price et al., 2007). This action research project concurs with this evidence, suggesting that the pre-assessment intervention may have improved performance and enhanced the quality of the student learning experience within an undergraduate occupational therapy module. The results indicated that a range of formative feedback opportunities across a curriculum, utilising different methods, may be most beneficial.

\section{Engagement and Support}

Students commented most frequently and most favourably on their improved engagement with the module, and on the sense of support they experienced as a result of the pre-assessment intervention. This was commented on with much more frequency and in much more depth than were expectations about performance changes. They experienced the pre-assessment intervention as a motivator, a method of increasing understanding, and a way to build confidence in their own work (Harris \& Bell, 1990; Mowl, 1996). The knowledge transfer method of building a shared understanding of assessment marking criteria was experienced as supportive, giving an opportunity to clarify and ask questions, and students who reflected on the experience considered how they might make use of it differently in future, suggesting that future similar sessions may be beneficial.

\section{Standards and Diversity}

Accompanying the massification of education and recent government policies of widening participation in higher education has been a growing concern about the effect on educational standards: university entrance standards; standards of assessment at university; and the standard of degree qualifications generally; and that today's students are not well-prepared for university. The modularisation of courses and the inclusion of key or graduate skills have also led to concerns about watered-down content (James, 2007; Utley, 2003; Leathwood, 2005). However, what are considered high standards differ according to class, gender and cultural background. As universities become more diverse places, courses for health professionals are usually located in the new universities, and are likely to attract students from more diverse backgrounds (Watson, 2011). These courses do not have a long academic history and do not have a history of prestige 
associated with them. Students undertaking health professional education need to build practice and reflective skills, as well as the more traditional academic skills of critical analysis and discussion (Castle, 2006).

\section{The Transferring of Tacit Knowledge}

Rust et al. (2003) found that making assessment criteria and standards more transparent and understandable to staff and students alike was a worthwhile but much more complex and difficult task than they had previously appreciated. Verbal descriptions of standards can be a matter of degree rather than absolute positions, and criteria are subject to multiple interpretations. Rust $e t$ al. (2003) report initially attempting to tighten the marking criteria and not experiencing success; instead they found it more useful to tackle the difficulty of relinquishing the notion that academic standards can be documented and codified in a way that would be available to all the consumers of higher education. During the reflection and dissemination phases of the cycle, the researcher also struggled with this difficulty, but found the ability to use a pre-assessment intervention as a package was useful, at least in beginning to deal with this.

Assessment systems have been firmly rooted in academic cultures and their institutions, but as universities massify, the implications of this on different groups in the community and on those attending newer university courses such as health professional education, become more obvious. Teaching staff on newer university courses may have little else than established practices from traditional settings to base their methods on. Finding innovative new ways to tackle assessment in a widening higher education sector is not an option, it is a necessary requirement (Mowl, 1996).

\section{Limitations}

The study was conducted in the researcher's own institution, and with a cohort of students she regularly taught. Whilst this insider knowledge can be useful in action research, it may also have had a bearing on the process. Only one cohort of 40 students was formally studied, which limits the generalisability of the study's findings. The researcher completed this study as part of work towards a Post Graduate Certificate in Learning and Teaching (Higher Education), and modular work towards this influenced the questions asked and choice of intervention. The pre-assessment intervention chosen was not original, although to the researcher's knowledge had not been used within occupational therapy education previously.

\section{Conclusion and recommendations}

This small-scale action research project focussed on enhancing undergraduate occupational therapy student performance in an assessment task, by improving student understanding of the assessment criteria (Rust et al., 2003; Price et al., 2007). The pre-assessment intervention was not original and already had an established evidence base. There was however a lack of any kind of pedagogical evidence in the both the occupational therapy and health professional literature, particularly around assessment methods, and this gap had been clearly identified (Samuelowicz, 1987; Swanson et al., 1998; Seale et al., 2000; Chung \& Chow, 2004). 
An emancipatory action research process (Atwal, 2002) was used, with the aim to influence the wider organisation. The project resulted in an indication of improved student performance on a task which previous student cohorts had found very challenging. Most significantly, the majority of students involved reported an increase in engagement and a sense of support within the module following the pre-assessment intervention. The project was presented to the wider university staff team shortly after completion, resulting in a varied take up of recommendations. The principle recommendation as a result of the project was to either include some type of formative feedback, or use the specific pre-assessment intervention developed by Rust et al. (2003, Price et al., 2007), in all modules across an inter-professional health and social care pathway.

A pre-assessment intervention enables teaching staff to tease out, and make transparent, tacit knowledge that they use in assessment. This sharing of knowledge on assessment standards and requirements enables greater understanding for staff and students alike, and fits with the wise use of ever dwindling resources in an increasingly diverse and changing higher education sector.

Recommendations for future research include exploring:

- Different formative feedback methods and their effects both in higher education generally, and in the education of health professionals.

- How students use pre-assessment interventions and formative feedback to improve their ability to self-evaluate over time.

- What, if any, the relationship might be between improved student engagement and performance in academic work.

- Further exploration into learning and teaching methods for building practice and reflective skills, as well as critical analysis and discussion in the education of health professionals.

\section{Acknowledgements}

With thanks to Phil Poole and John Lea.

\section{References}

Adelman, C. (1989) The practical ethic takes priority over methodology. In Carr, W. (ed) Quality in Teaching: Arguments for a Reflective Profession. London: Falmer Press.

Atwal, A. (2002) 'Getting the evidence into practice: the challenges and successes of action research'. British Journal of Occupational Therapy. 65 (7): 335-341.

Beer, M., Eisenstat, R. A. and Spector, B. (1990) 'Why change programmes don't produce change'. Harvard Business Review. November-December: 4-12.

Carr, W. and Kemmis, S. (1986) Becoming Critical: Education, Knowledge and Action Research. Oxon: Deakin University Press. 
Castle, A. (2006) 'Assessment of the critical thinking skills of student radiographers'. Radiography. 12 (2): 88-95.

Caygill, R. and Eley, L. (2001) Evidence about the effects of assessment task format on student achievement. Paper presented at the Annual Conference of the British Educational Research Association, University of Leeds, September 2001. Available online: http://www.leeds.ac.uk/educol/documents/00001841.htm (accessed 26th June 2012).

Cohen, L., Manion, L. and Morrison, K. (2000) Research Methods in Education. Fifth edition. London: Psychology Press.

Chung, J. C. C. and Chow, S. M. K. (2004) 'Promoting student learning through a studentcentred problem-based learning subject curriculum'. Innovations in Education and Teaching International. 41 (2): 157-168.

Eden, C. and Huxham, C. (1993) Distinguishing Action Research. Working paper 93/18. Paper presented at the British Academy of Management Conference, September 1993, Milton Keynes, UK.

Harris, D. and Bell, C. (1990) Evaluating and Assessing for Learning. London: Kogan Page.

Hart, E. and Bond, M. (1995) Action Research for Health and Social Care: A Guide to Practice. Buckingham: Open University Press.

Holter, I. M. and Schwartz-Barcott, D. (1993) 'Action research: what is it? How has it been used and how can it be used in nursing? Journal of Advanced Nursing. 18( 2): 298-304.

James, R. (2007) Briefing paper: Students and student learning in mass systems of higher education: six educational issues facing universities and academic leaders. Paper prepared for the seminar series Mass Higher Education in UK and International Contexts, May 2007, Surrey. Available online:

http://www.crll.org.uk/media/crll/content/publications/massheseminar/Seminar\%203\%20Richar dJames\%20Briefing\%20Paper.pdf (accessed 26 ${ }^{\text {th }}$ June 2012).

Knight, P. T. (2002) 'Summative assessment in higher education: practices in disarray'. Studies in Higher Education. 27 (3): 275-286.

Leathwood, C. (2005) 'Assessment policy and practice in higher education: purpose, standards and equity’. Assessment and Evaluation in Higher Education. 30 (3): 307-324.

Lewin K. (1952) Field Theory in Social Science: Selected Theoretical Papers by Kurt Lewin. London: Tavistock.

Meyer, J. (2000) 'Using qualitative methods in health related action research'. British Medical Journal. 320: 178-81. 
Mowl, G. (1996) Innovative Student Assessment. Deliberations. London Metropolitan University. Available online:

http://www.londonmet.ac.uk/deliberations/assessment/mowl.cfm (accessed 26th June 2012).

O’Donovan, B., Price, M. and Rust, C. (2004) 'Know what I mean? Enhancing student understanding of assessment standards and criteria'. Teaching in Higher Education. 9 (3): 325335.

Orsmond, P., Merry, S. and Reiling, K. (2005) 'Biology students' utilisation of tutors' formative feedback: a qualitative interview study'. Assessment \& Evaluation in Higher Education. 30 (4): 369-386.

Price, M., O’Donovan, B. and Rust, C. (2007) 'Putting a social constructivist assessment process model into practice: building the feedback loop into the assessment process through peer review'. Innovations in Education and Teaching International. 44 (2): 143-152.

Rust, C., Price, M. and O’Donovan, B. (2003). 'Improving students' learning by developing their understanding of assessment criteria and processes'. Assessment \& Evaluation in Higher Education. 28 (2): 147-164.

Samuelowicz, K. (1987) 'Learning problems of overseas students: Two sides of a story'. Higher Education Research \& Development. 6 (2): 121-133.

Swanson, D., Norman, G. R. and Linn, R. L. (1998) 'Performance based assessment: Lessons from the health professions'. Educational Researcher. 24 (5): 5-11.

Seale, J. K., Chapman, J. and Davey, C. (2000) 'The influence of assessment on students' motivation to learn in a therapy degree course. Medical Education. 34 (8): 614-621.

Utley, A. (2003) 'Influential teaching technique rubbished'. Times Higher Educational Supplement. 28 November.

Watson, J. (2011) Progression routes and attainment in occupational therapy education: The impacts of student background characteristics. Paper presented at British Educational Research Association Annual Conference, London.

Winter, R. (1989) Learning From Experience: Principles and Practices in Action Research. London: Falmer Press.

Zuber-Skerritt, O. (1996) Emancipatory action research for organisational change and management development. In Zuber-Skerritt, O. (ed) New Directions in Action Research. London: Falmer Press. 


\section{About the author}

Anita Volkert is a Senior Lecturer in Occupational Therapy at Leeds Metropolitan University.

Email: A.G.Volkert@ leedsmet.ac.uk 